\title{
STUDIES OF ACOUSTIC EMISSION FROM POINT AND EXTENDED SOURCES
}

\author{
Wolfgang Sachse, Kwang Yul Kim, and C.P. Chen \\ Cornell University \\ Ithaca, New York 14853
}

The use of simulated and controlled acoustic emission signals forins the basis of a powerful tool for the detailed study of various deformation and wave interaction processes in materials. We report the results of experiments and signal analyses of $A E$ resulting from point sources such as various types of indentation-produced cracks in brittle materials and the growth of fatigue cracks in 7075-T6 aluminum panels. Fur thermore, we describe our recent work dealing with the modeling and subsequent signal processing of an extended source of emission in a material. Results of the forward problem and the inverse problem are presented with the example of a source distributed through the interior of a specimen shown.

\section{INTRODUCTION}

The use of acoustic elnission (AE) signals for real-tine structural integrity monitoring applications has long been sought. Developments over the last several years have gone far towards obtaining a better understanding of the $A E$ process in actual structural components (Refs. 1-5). These include the development of a model consisting of a repeatable source of known type, a structure for which the propagation of transient elastic waves can be computed, sensors whose transfer characteristics are either known or can be deterinined experimentally and the development of new signal processing algorithrns for analyzing the detected signals.

The associated problem, sometines called the "inverse source problem", has as its aim the characterization of a source in terms of its location in the structure, its type, specified in terms of force or moment tensor components, its spatial distribution, if the source is extended, and its temporal or dynamic characteristics. This paper gives an overview of the work recently completed in our laboratory on aspects of this topic.

\section{THEORY AND WAVEFORM PROCESSING}

The displacement signals $u_{k}$ detected at a receiver location, $x$, in a structure from an arbitrary source $f\left(x^{\prime}, t\right)$ located at ${ }^{k} x^{\prime}$ having source volume $v_{0}$ can be written as

$$
u_{k}=\int_{V} f_{j}\left(x^{\prime}, t\right) * G_{j k}\left(x / x^{\prime}, t\right) d V
$$

where the term $G_{j k}$ represents the Green's function of the structure. Insight into this formulation can be obtained if one makes a Taylor series expansion of the Green's function about the source point, $x^{\prime}$, located at, say 0 , to give

$$
u_{k}(x, t)=\int_{V_{0}} f_{j}(0, t) * G_{j k}(x / 0, t) d V+\int_{V} x_{0}^{x} f_{j}(0, t) * G_{j k, i}(x / 0, t) d V^{\prime}
$$


The first term in this equation, representing the monopole contribution, can be rewritten in the form

or

$$
u_{k}^{(m)}=\left\{\int_{V} f_{0}(0, t) d V\right\} * G_{j k}(x / 0, t)
$$

$$
u_{k}^{(m)}=s_{j}(t) * G_{j k}(x / 0, t)
$$

The second term in Eq. (2), representing the dipole contribution, can be rewritten in a similar fashion as

or

$$
u_{k}^{(d)}=\left\{\int_{V_{0}^{x_{i}^{\prime}}} f_{j}\left(x^{\prime}, t\right) d V^{\prime}\right\} * G_{j k, i}(x / 0, t)
$$

$$
u_{k}^{(d)}=M_{i j}(t) * G_{k, i}^{\prime}(x / 0, t)
$$

The term, $M_{i j}$, called the moment tensor of the source, can be used to represent any combination of double forces (Ref. 3) to model the source. It can be shown that the moment tensor can be written in terms of the crack's displacement jump and its area in a material (Ref. 6). If each of the components of the moment tensor of the source have the same time dependence, then the spatial and temporal characteristics of the source are separable. Thus, the moment tensor can be written as a product of the moment density tensor, $\mathrm{m}_{\mathrm{ij}}$, and the and the source-time function, $S(t)$,

$$
\mathrm{M}_{\mathrm{ij}}=S(t) \cdot \mathrm{m}_{\mathrm{ij}}
$$

In recovering the characteristics of a dipolar source from the measured signals, $u_{z}$, one uses knowledge of the Green's function $G$ and inverts Eq. (4) to recover $S(t)$ and the components $\mathrm{m}_{\mathrm{ij}}$. In the most complicated deformation processes and for an arbitrary crack orientation, all six components of the mornent density tensor may need to be evaluated. As of now, this has not yet been done. Here we show the results obtained for several simpler cases.

The simplest case is that of a point source of known type for which only the temporal aspects of the source are to be recovered from the detected signals. In that case, Eq. (3) can be rewritten as a simple convolution equation in time

$$
u(t)=S(t) * G(t)
$$

This equation has been modified to include the transfer characteristics of a non-displacement transducer, whose response is band-limited. Recovery of the source function, $S(t)$, then involves two measurements, one of which is a calibration experiment using a known step excitation source applied at the source position. Examples of processing near-field and farfield signals from an axisymınetric source have been published previously (Refs. 7-9).

For the case described by Eq. (4) in which both the time-function and moment-density tensor components of a source are to be recovered, several processing algorithms have been developed. One of these is based on an algebraic scheme in which the amplitudes of particular ray arrivals in the detected signals are directly related to the amplitudes of the Green's function (Ref. 10). Once these are determined, the source tirne-function can be recovered as before. The problems related to this scheme result principally from the amplitude 
measurernent precision required of specific features on a waveform. An alternative is a double iterative scheme demonstrated by Michaels and Pao (Ref. 9). The procedure is initiated with a guess of the moment tensor magnitudes from which a solution of the source time-function is obtained. This solution is used, in turn, to evaluate a new set of moment tensor arnplitudes, and so on. The iteration process is continued until the results obtained in the iterations converge to a final answer. The procedure appears to be initial guess dependent and it may also converge slowly for certain configurations of the source moment tensor. It has been found that an appropriate initial guess for the double-iterative scheme can be obtained by making use of the results obtained from the algebraic processing scheme.

\section{RESULTS}

Demonstration of any signal analysis procedure for AE source characterization must begin with a controlled deformation process in a material. Reproducible, deformation-related AE sources whose location is known precisely, include indentation-produced cracks in brittle materials and fatigue-generated cracks in thin specimens and these were investigated in this work.

\section{a. Fatigue Cracks}

In detailed fatigue experiments, conventional test parameters were recorded in combination with electrical crack length measurements and a total of five AE waveforms, detected at points around the crack region. Two sample signals recorded equidistant from the crack front are shown in Figure l. The four equivalent forces or moment tensor components by which an arbitrary dipolar source in a thin specimen can be modelled are shown schematically in Figure 2. It is found that the dynamic Green's functions corresponding to the $M_{12}$ and $M_{21}$

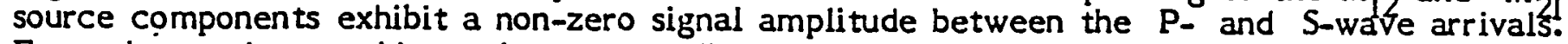
From observations as this, each corresponding to an event, it is concluded that only two signals are needed to determine without ambiguity the characteristics of the source. It was found that some of the events could be adequately described in terms of only two double forces, i.e.; $M_{11}$ and $M_{22}$. Other events required also a contribution from the $M_{12}$ and $M_{21}$ components. Table 1 shows the results obtained for two events one of each type. Hore than thirty-eight signals were processed in a typical test. In Figure 3 is the recovered source-time function obtained with the double-iterative processing scheme. It appears that the crack displacement profile had a risetime of approximately $400 \mathrm{nsec}$. The risetime may actually be shor ter than this, since the recovered value corresponds to the upper bandwidth limit of the transducer/amplifier system.

\section{b. Indentation Cracks}

The pressing of an indentor onto the surface of a flat plate results in a stress field configuration which depends on the shape of the indenter and the mechanical properties of the plate specimen. If the specimen is a brittle material, cracks of specific shape for $m$ when and in those regions where the stress field exceeds the fracture strength of the material. The dynamic force released in forming the crack is emitted as an AE signal. A typical epicentral AE signal obtained with a spherical-tipped indenter is shown in Figure 4(a). Typical Hertzian cone cracks are obtained when such indenters are pressed against a specimen. It has been shown that the associated dynamic source is equivalent to a vertical axisymmetric force acting on the structure (Ref. 11). On unloading, one or more lateral vent cracks may form whose associated $A E$ signals exhibit completely different characteristics as shown in Figure 4(b). In some cases, these may be adequately modelled by a single horizontal dipole acting near the surface of the plate. This appears to be the case, when only one lateral vent crack forms. The detected AE 
signals resemble those obtained when a conical indenter is pressed against the specimen. In the latter situation, a single penny-shaped crack is formed. Evaluation of the stress field under the conical indenter, obtained from the Boussinesq solution (Ref. 12), shows regions of tensile and compressive hoop stresses. The crack is generated in the region of tensile hoop stresses whose contours resemble a penny.

Experiments were carried out with an eight-channel $A E$ system consisting of point piezoelectric transducers with a $1.2 \mathrm{~mm}$ active area situated at various angles at a distance approximately $2 \mathrm{~h}$ ( $\mathrm{h}$ - plate thickness) from the indenter. Sensors whose response was nearly uniform in amplitude were selected for the array. The signals were amplified by $60 \mathrm{~dB}$ with preamplifiers whose bandwidth ranged from $10 \mathrm{kHz}$ to $2 \mathrm{MHz}$. They were subsequently digitized in transient waveform recorders operating at a sampling rate of $30 \mathrm{MHz}$ with 10-bit resolution.

Evaluation of the moment tensor components of the penny-shaped crack via one of the procedures. listed in the previous section often did not yield reliable results, as they were strongly initial guess dependent. It was clear, however, when comparing the detected waveforms to synthesized $A E$ signals, that the model of a tensile crack given in terms of three or thogonal dipoles of strength, $\lambda+2 \mu, \lambda$ and $\lambda$, where $\lambda$ and $\mu$ are the Lame constants, may not be appropriate to model an indentation-produced crack in a small specimen as described here.

An alternative approach for recovering the ratios of the moment tensor components involves measurement of the radiated field of the AE signal from the source. The radiated amplitude measured at a distance $R$ from a dipolar source, can be written in terms of the displacement amplitude, $u_{z}$, and this is expected to be of the form

$$
u_{z}(R, t)=a_{1}(t)+a_{2}(t) \cos ^{2} \theta
$$

where $\theta$ is the orientation of the normal to the crack. For a single horizontal dipole source, aligned parallel to the crack normal, the term $a_{1}(t)$ is expected to be near zero. For threedipole crack model, its value is expected to be approximately 0.28 . Eq. (7) can be rewritten to account for an arbitrary crack orientation relative to the sensor array

$$
u_{z}(R, t)=a_{1}(t)+a_{2}(t) \cos ^{2}\left(\theta-\theta_{c}\right)
$$

where $\theta_{c}$ is the orientation of the normal of the crack relative to the orientation of the sensor array.

By a proper choice of angular distribution of sensors around the indenter, an eight-channel $\mathrm{AE}$ system is adequate to determine the field characteristics of the indentation-generated cracks. Each channel of the entire system was calibrated simultaneously by breaking a glass capillary $0.05 \mathrm{~mm}$ in diameter at the crack position on the specimen. The result was an axisymmetric step excitation source. The amplitudes of both the first P- and S-wave arrivals were measured. The corresponding amplitudes in the crack-generated signals were normalized with the calibration amplitudes. The result obtained after one indentation is shown in Figure 5. The solid and dasined lines correspond to the results produced from a non-linear least-square fit of Eq. (8) to the measured data. From the curve fit, the parameters of the radiated field can be extracted. Once these are known, the measured amplitudes at each transducer can be reflected across the various symmetry planes to generate image data points with the results obtained shown in Figure 6. Inspection of the amplitude ratio $a_{1} / a_{2}$ shows that the tensile cracks produced by the conical indenter are best modelled as resulting principally from a single 
horizontal dipole. The orientation of the $\mathrm{crack}$, relative to the array configuration, is recovered immediately when Eq. (8) is fit to the amplitude data. The difference between the observed and recovered crack orientation angle from seven indentations was always less than $6^{\circ}$ and on average less than $3^{\circ}$.

The radiated field of the signals emitted from lateral vent unloading cracks was also measured. It was found that the formation of multiple cracks results in a radiated field which radiate more uniformly in all directions and clearly, the radiation does not resenble that of a single crack.

It is possible to process an epicentral displacement signal with the double-iterative processing scheme to recover the individual magnitudes of the moment tensor as well as their time function. Figure 7 shows the recovered source time function for an indentation crack.

\section{EXTENDED SOURCE}

Both the forward and inverse problems of the extended source have been solved using synthetic data. A series of examples dealing with two source types and several linear distributions on the surface or through the interior of a plate specimen have been computed (Ref. 13). In Figure $8(a)$ is shown the case of a distribution of horizontal dipole sources, extending to $0.75 \mathrm{~h}$ into the interior of the plate and whose time function was a Heaviside step function. It has been proposed that such a source may be used to model the interaction of intense synchrotron-generated pulses of $x$-rays striking a specimen and penetrating into its interior (Refs. 14-15). Figure 8(b) shows a comparison between the signal from a single dipole very close to the top surface of the specimen and the signal synthesized from forty source points whose strength distribution along the $z$-axis was given by $e^{-0.5 z}$. After only ten iterations in the double-iterative processing scheme, the input source function was recovered from the synthetic input data within a percent and the corresponding recovered source time function was indistinguishable from the input.

\section{CONCLUSIONS}

Acoustic emission signals detected from cracks formed during indentation and fatigue loading experiments have been processed to recover the moment tensor components of the crack source and their time function. Several signal processing schemes were demonstrated including one based on ray amplitude measurements, a double-iterative processing scherne and an AE radiation pattern analysis method. A signal processing algorithm was also demonstrated with synthetic AE waveforms corresponding to an extended source of emission by which the signals can be processed to recover both the spatial extent of the source and its time function.

\section{ACKNOWLEDGMENTS}

This work was supported by the National Science Foundation through grants to the Materials Science Center and to the College of Engineering at Cornell University. A significant portion of the equipment used in the experiments described was acquired through a DoD Instrumentation Grant awarded through the Office of Naval Research. 


\section{REFERENCES}

(1) R. F. Breckenridge, C. E. Tschiegg and M. Greenspan, "Acoustic Emission: Some Application of Lamb's Problem", J. Acoust. Soc. Am., 57, 626-631 (1975).

(2) N. N. Hsu, J. Simmons and S. C. Hardy, "An Approach to Acoustic Emission Signal Analysis - Theory and Experiment", Matls. Eval., 35(10), 100-106 (1977).

(3) Y. H. Pao, "Theory of Acoustic Emission", in Elastic Waves and Non-destructive Testing of Materials, Y. H. Pao, Ed., AMD-Vol. 29, Am. Soc. Mech. Engrs., New York (1978), pp. 107-128.

(4) N. N. Hsu and S. C. Hardy, "Experiments in Acoustic Emission Waveform Analysis for Characterization of AE Sources, Sensors and Structures", in Elastic Waves and Nondestructive Testing of Materials, Y. H. Pao, Ed., AMD-Vol. 29, Am. Soc. Mech. Engrs., New York (1978), Pp. 85-106.

(5) H. N. G. Wadley and C. B. Scruby, "Quantitative Acoustic Emission Studies during Deformation and Fracture: A Review", Report AERE - R 10353, AERE Harwell, Oxfordshire (1981).

(6) K. Aki and P. G. Richards, Quantitative Seismology, Vol. 1, W. H. Freeman and Co., San Francisco (1980), Chapt. 4.

(7) J. E. Michaels, T. E. Michaels and W. Sachse, "Applications of Deconvolution to Acoustic Emission Signal Analysis", Materials Evaluation, 39(11), 1032-1036 (1981).

(8) P. N. Hsieh and W. Sachse, "Far-field Signals from Axis-symmetric Sources in Elastic Plates", in Ultrasonics International '83 - Conference Proceedings, Butterworth and Co. Publ., Sevenoaks, Kent, UK (1983), pp. 388-394.

(9) J. E. Michaels and Y. H. Pao, "Deconvolution of Source Time Functions of the Moment Density Tensor", in Review of Progress in Quantitative NDE, D. O. Thompson and D. E. Chimenti, Eds., Plenum Press, New York (1984), pp. 707-715.

(10) C. P. Chen, "Acoustic Emission Source Characterization of Fatigue Cracks in 7075-T6 Aluminum Alloy Thin Plate", Ph. D. Dissertation, Cornell University, Ithaca, NY (1985).

(11) K. Y. Kim and W. Sachse, "Characteristics of Acoustic Emission Signals of Hertzian and Unloading Cracks in Glass", J. Appl. Phys., 55, 2847-2856 (1984).

(12) I. N. Sneddon, "Boussinesq's Problem for a Rigid Cone", Proc. Cambridge Phil. Soc., 44, 492- (1948).

(13) C. Chang and W. Sachse, "Analysis of Elastic Wave Signals from an Extended Source in a Plate", J. Acoust. Soc. Am., 77, 1335-1341 (1985).

(14) K. Y. Kim and W. Sachse, "X-ray Generated Ultrasound", Appl. Phys. Letts., 43, 10991101 (1983).

(15) W. Sachse and K. Y. Kim, "Observation of X-ray Generated Ultrasound", 1983 Ultrasonics Symposium, Inst. Elect. Electr. Engs., New York (1983), pp. 677-680. 
$U_{2}=C_{11} G_{21,1}+C_{22} G_{22,2}+C_{12} G_{21,2}+C_{21} G_{22,1}$

Event \#34; Model: Two Double Forces

Algebraic; $C_{11}: C_{22}=1: 0.258$

Double Iteration; $C_{11}: C_{22}=1: 0.266$

Event \#35; Model: Two Double Forces, Two Single Couples

Algebraic ; $C_{11}: C_{22}: C_{33}: C_{44}=1: 0.324:-0.271: 0.237$

Double Iteration; $C_{11}: C_{22}: C_{33}: C_{44}=0.996: 0.308:-0.271: 0.209$

Table I 
FATIGUE CRACK: SENSIR \# 1

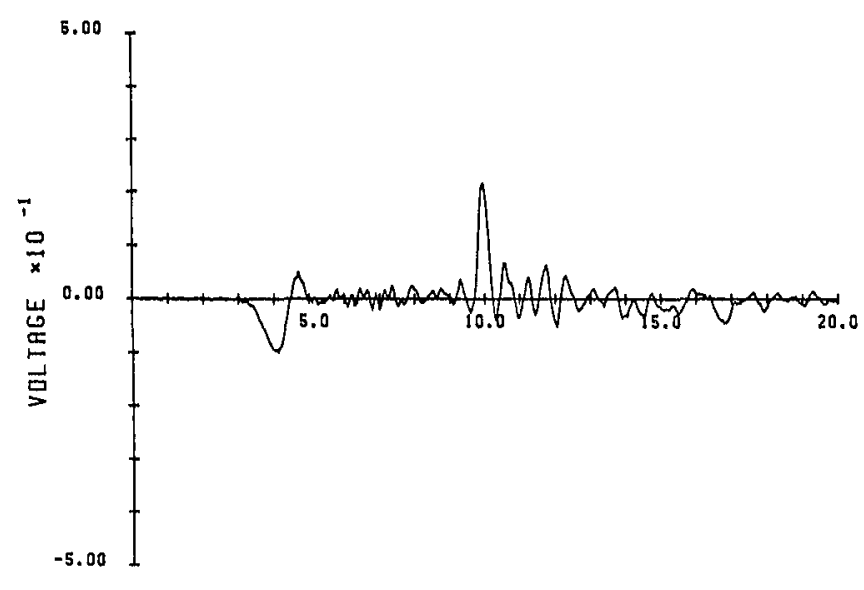

TIME (useo)

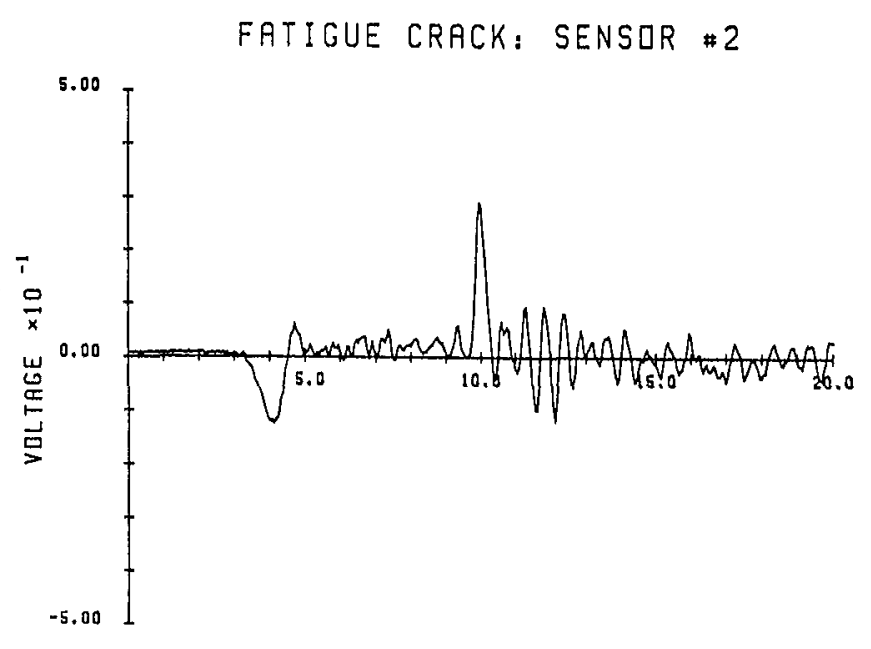

TIME (useo)

Figure 1

EQUIVALENT FORCES / MOMENT TENSOR COMPONENTS

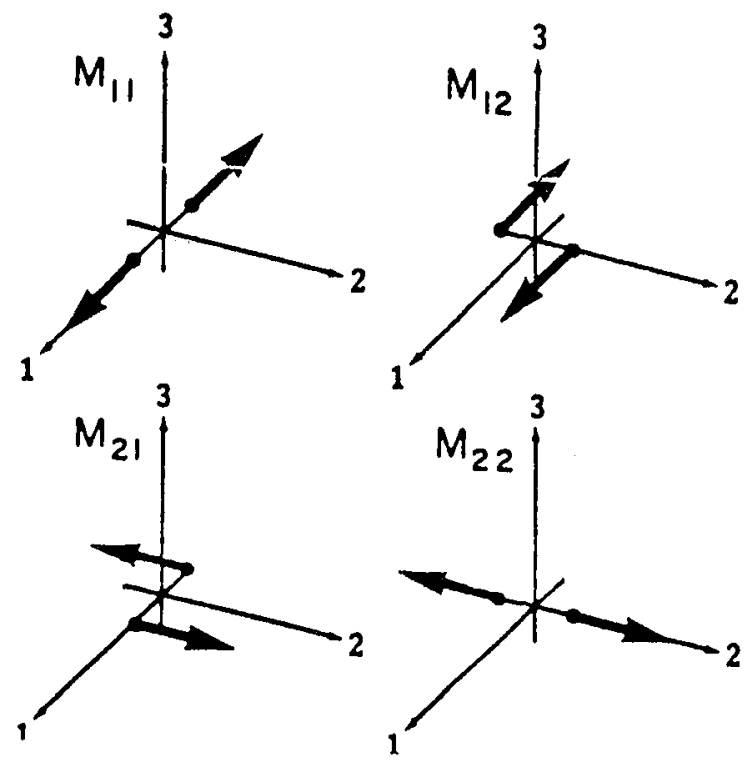

Figure 2 

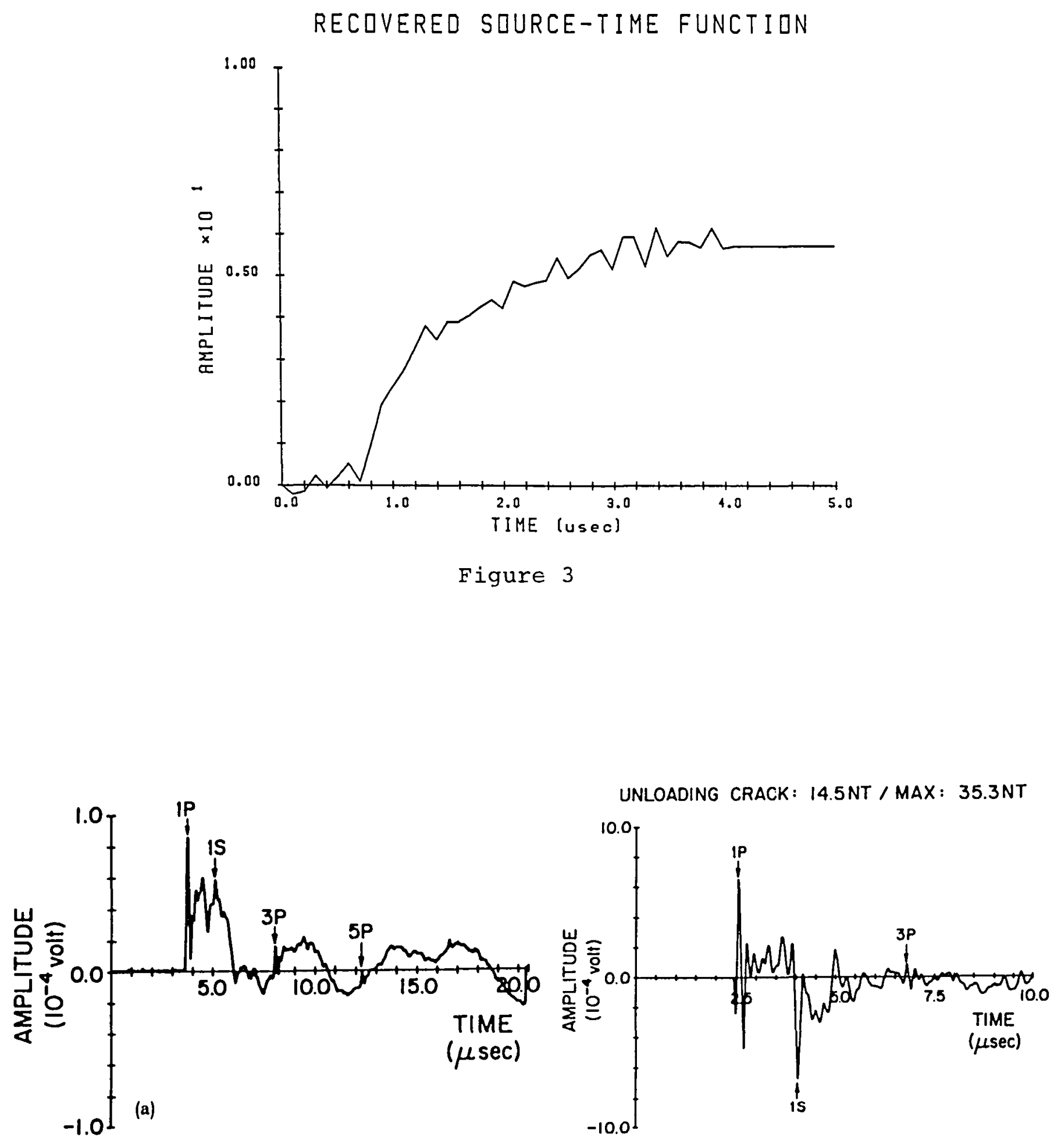

Figure $4(a)$

Figure 4(b) 
$120^{\circ}$ CONICAL INDENTER - DIPOLE RADIATION

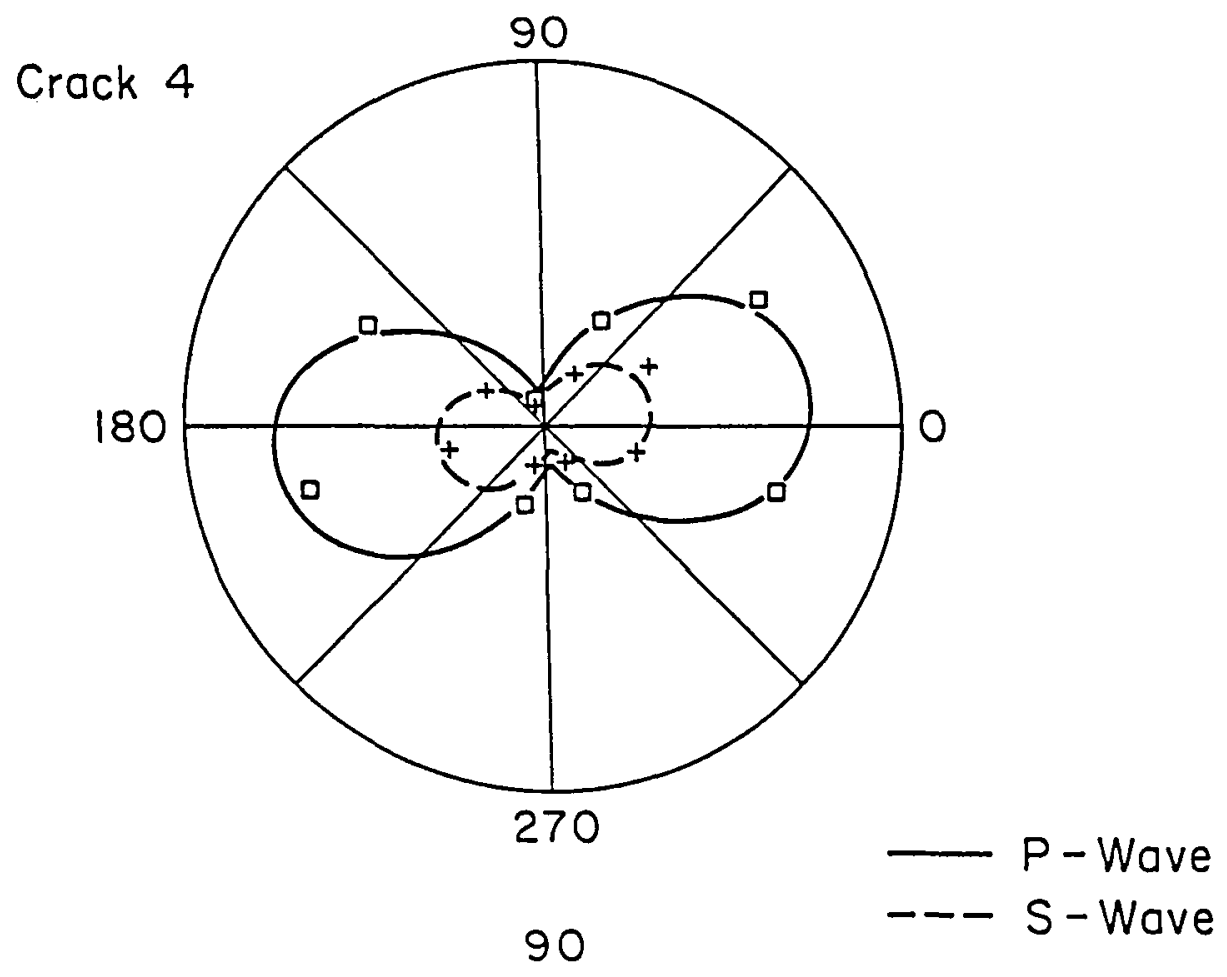

Figure 5

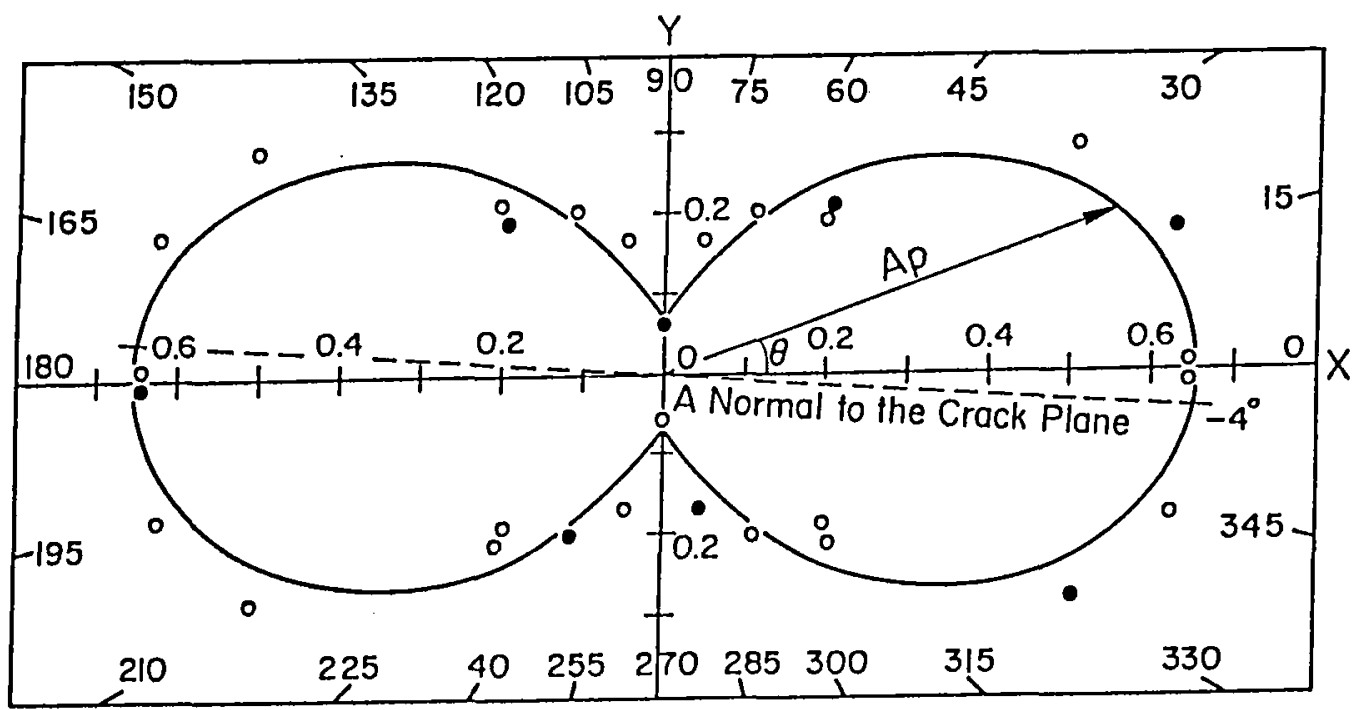

- -Real Data points, o-Images across $X, Y$ Axes; $A p=0.585\left(0.123+\cos ^{2} \theta\right)$

Figure 6 
RECOVERED SOURCE - TIME FUNCTION (CRACK 9)

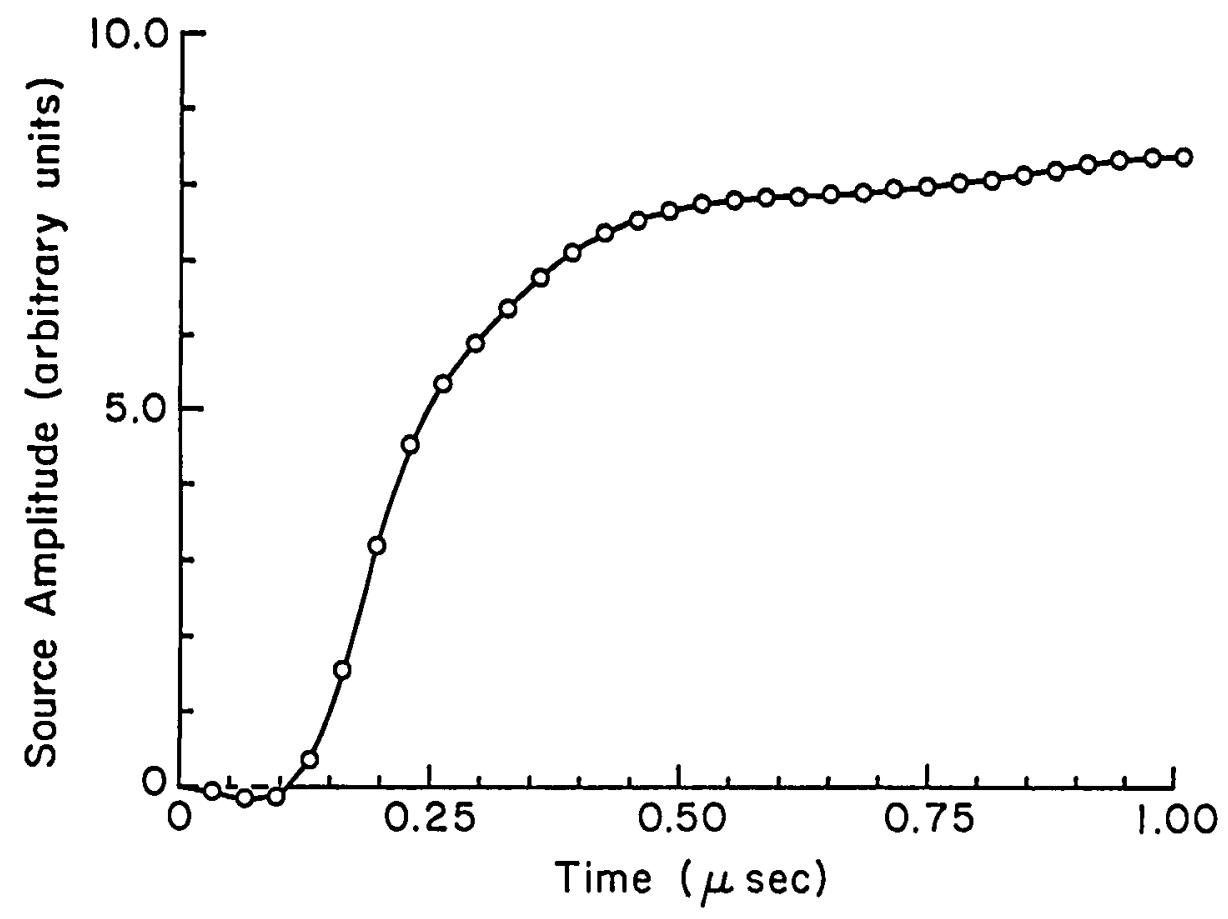

Figure 7

HORIZONTAL DIPOLES

$(0.0-0.75 h)$

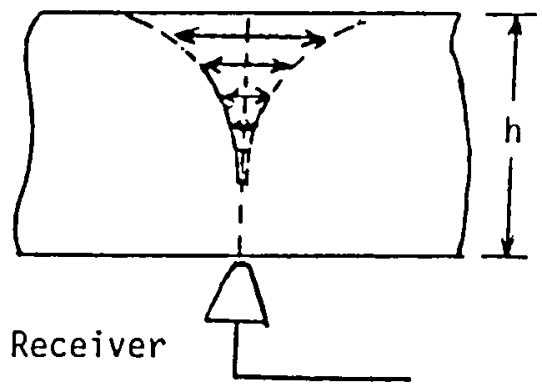

Extended dipole source model

Figure $8(a)$
DIPOLE SOURCES: EXPONENTIAL DISTRIB

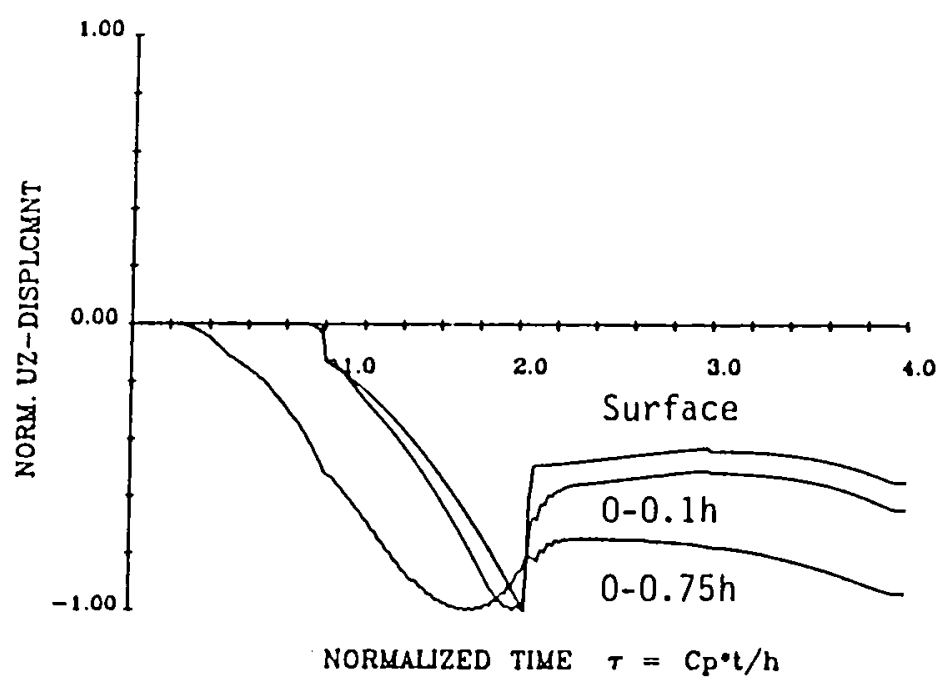

Synthetic normal displacement signals corresponding to several source distributions

Figure $8(\mathrm{~b})$ 